\title{
Analisis Peran Pelibatan Praktisi Swasta (Dokter Praktik Mandiri dan Klinik Pratama Swasta) dalam Public Private Mix TB di Kota Yogyakarta
}

Latar Belakang: Sebuah penelitian tentang Patient Pathway Analysis (PPA) Tuberkulosis (TB) level nasional dan sub nasional mengungkapkan bahwa hanya $32 \%$ kasus ternotifikasi, sehingga diperkirakan terdapat $68 \%$ kasus yang hilang. Mayoritas dari kasus yang hilang ini diperkirakan ada pada sektor swasta dan tidak terlaporkan Upaya penanggulangan TB telah mengembangkan prinsip pendekatan terpadu pemerintah dan swasta atau Public Private Mix (PPM) yang melibatkan seluruh penyedia pelayanan pemerintah masyarakat (sukarela), perusahaan dan swasta. Pelibatan praktisi swasta memiliki dampak penting terhadap perbaikan program penemuan dan pengobatan TB dan pencegahan meluasnya kasus TB resisten obat. Penanggulangan TB di Kota Yogyakarta telah melibatkan Rumah Sakit swasta dalam Hospital DOTS Linkage, namun Dokter Praktik Mandiri dan Klinik Pratama swasta belum terlibat. Kecamatan Umbulharjo dan Kecamatan Gondokusuman termasuk wilayah dengani beban TB tinggi dan terdapat banyak praktisi swasta di Kota Yogyakarta. Belum terdapat penelitian yang menilai pelibatan praktisi swasta di Kota Yogyakarta.
Tujuan: Menganalisis peran pelibatan praktisi swasta (Dokter Praktik Mandiri dan Klinik Pratama Swasta) dalam penanggulangan TB di Kota Yogyakarta.

Metode: Penelitian ini menggunakan rancangan kualitatif. Subjek penelitian adalah praktisi swasta (Dokter Praktik Mandiri dan Klinik Pratama Swasta) di Kecamatan Umbulharjo dan Gondokusuman, pemegan program TB Dinas Kesehatan Provinsi DIY dan Kota Yogyakarta, Kepala Puskesmas dan pemegang program TB Puskesmas, organisasi pofesi (IDI). Metode pengumpulan data yang akan dilakukan adalah wawancara mendalam.

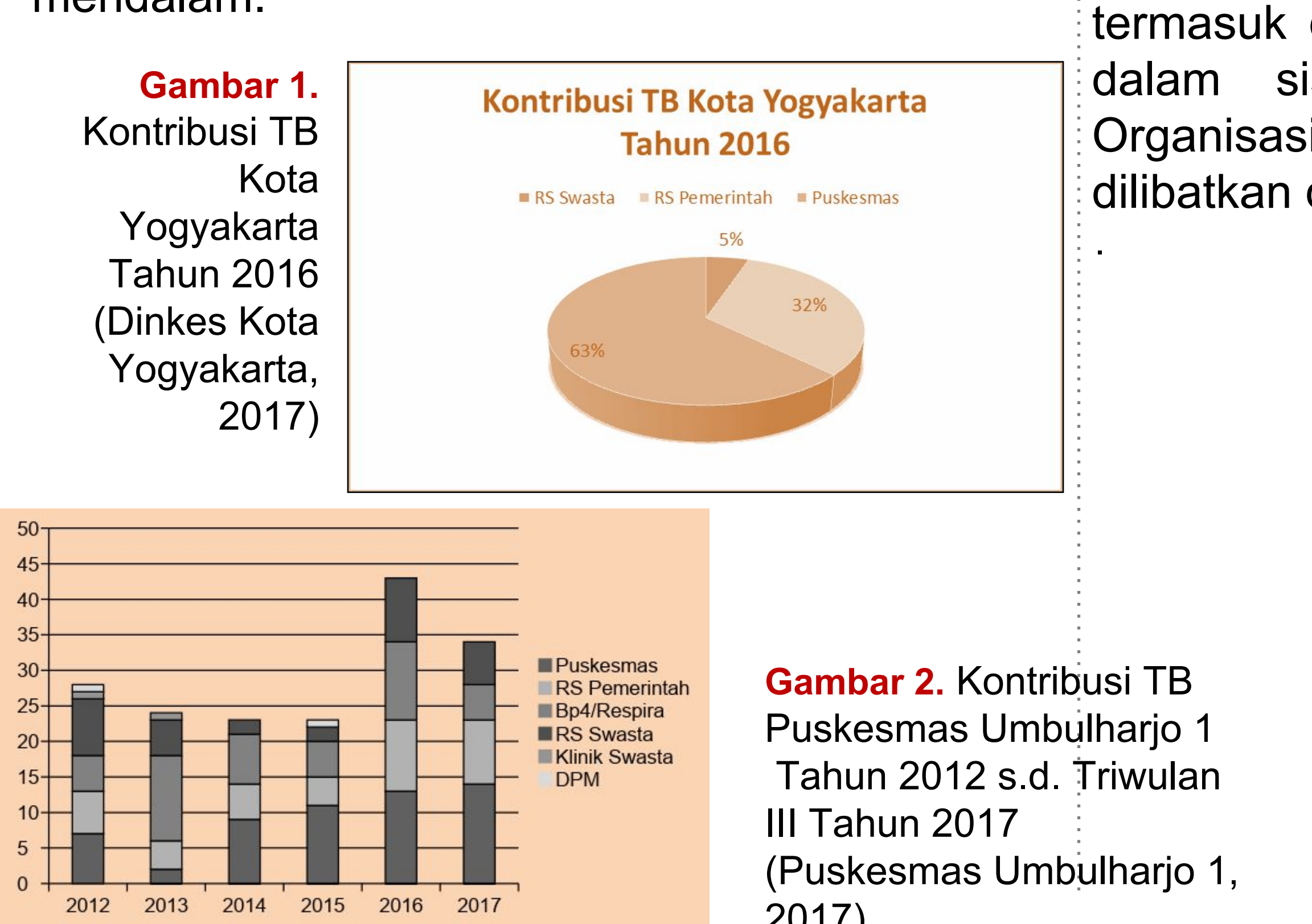

(Puskesmas Umbulharjo 1
Hasil: Praktisi swasta yang terdiri dari 9 Dokter Praktik Mandiri (4 dokter umum, 2 dokter Spesialis Paru, 2 dokter Spesialis Anak, 1 dokter Spesialis Penyakit Dalam) dan 6 dokter umum Klinik Pratama swasta mengungkapkan bahwa mereka merasa kurang dilibatkan dalam penanggulangan TB namun menyatakan siap berkontribusi sesuai porsinya dan mengusulkan penggunaan teknologi informasi yang praktis dalam keterlibatan notifikasi kasus. Dinas Kesehatan telah menerbitkan Rencana Aksi Daerah TB namun sistem teknis pelibatan praktisi swasta belum diprioritaskan. Kepala Puskesmas kurang menjalankan fungsi kepemimpinannya sebagai penanggungjawab kewilayahan dalam hal pelibatan praktisi swasta sistem PPM TB di wilayahnya. rganisasi profesi (IDI) belum sepenuhnya batkan dalam penanggulangan TB.

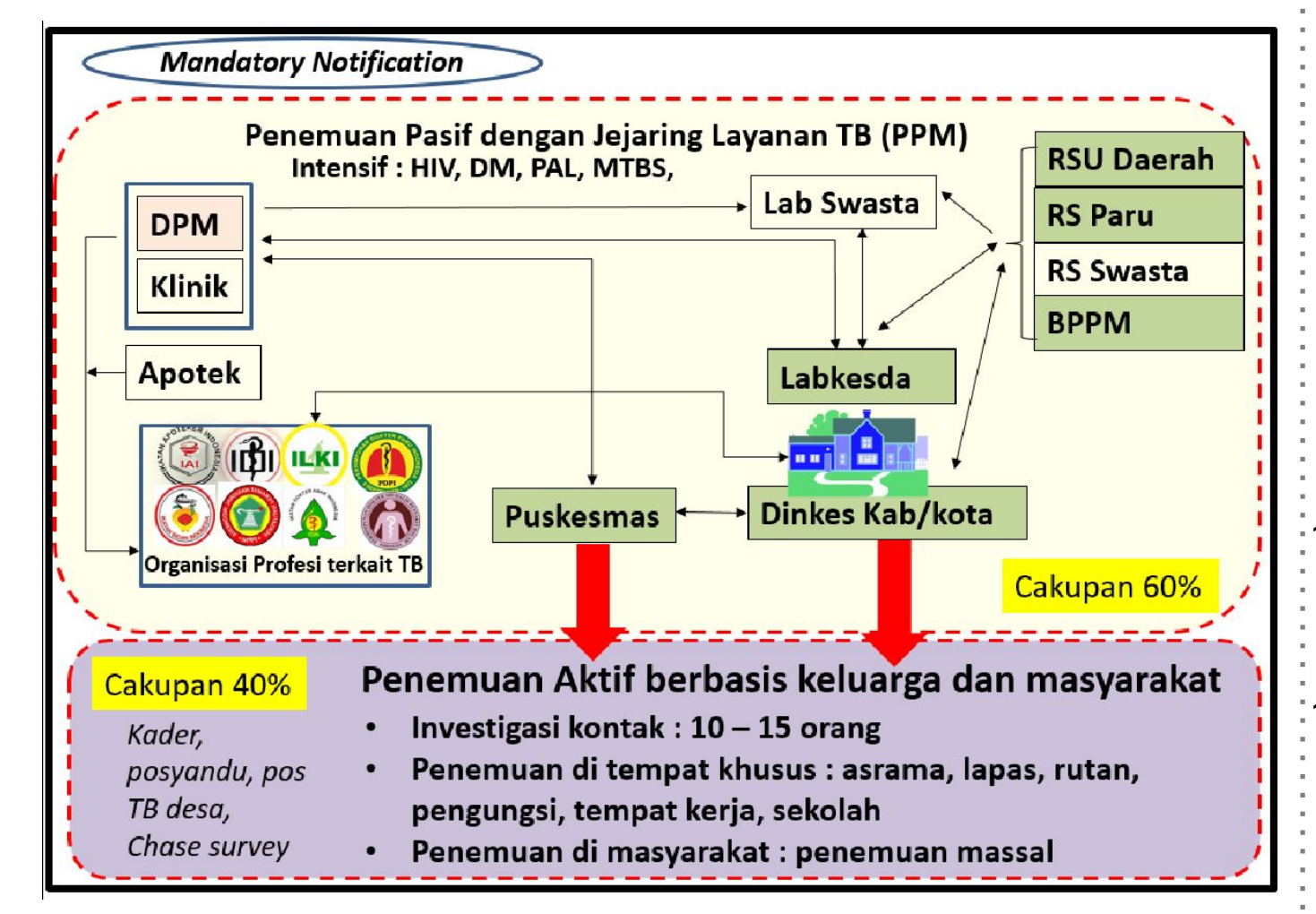

Gambar 3. Jejaring Layanan TB (PPM TB)
Kesimpulan: Peran Dinas Kesehatan sebaga perancang dan penggerak sistem PPM cukup mendasar, namun peran vital kepemimpinan inovatif Kepala Puskesmas sebagai penanggungjawab kewilayahan sangat dibutuhkan untuk mampu menggerakkan sistem PPM termasuk upaya pelibatan praktis swasta.

Kata Kunci: Tuberkulosis, Public Private Mix pelibatan praktisi swasta, kepemimpinan inovatif

Referensi

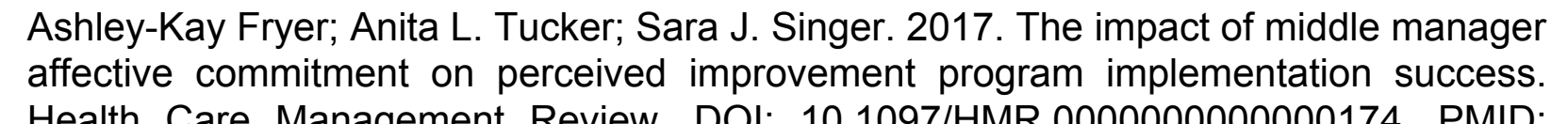

\section{Cam 2870}

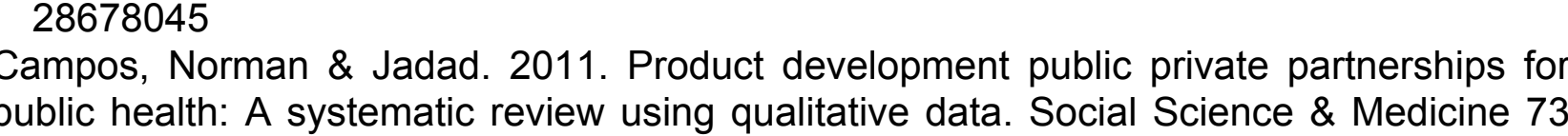
Chadha a etal 2017. Mendary

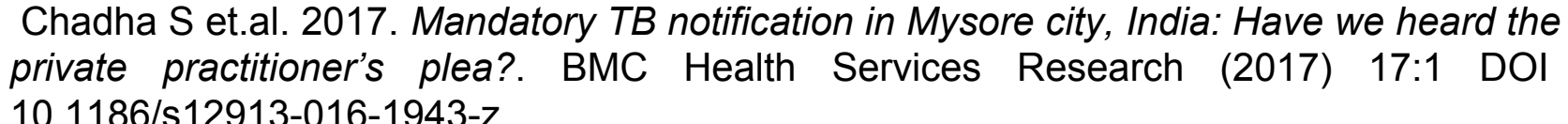

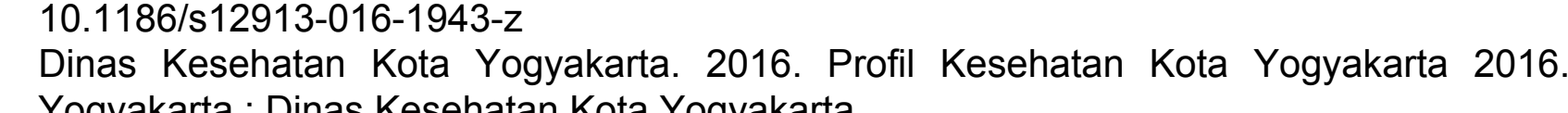

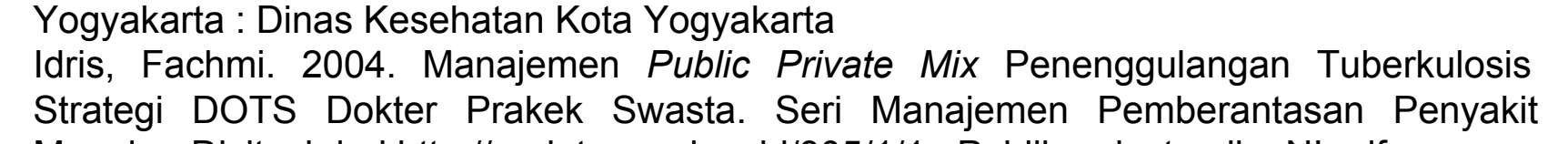

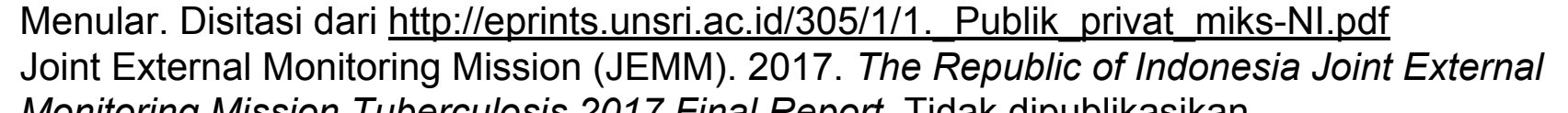

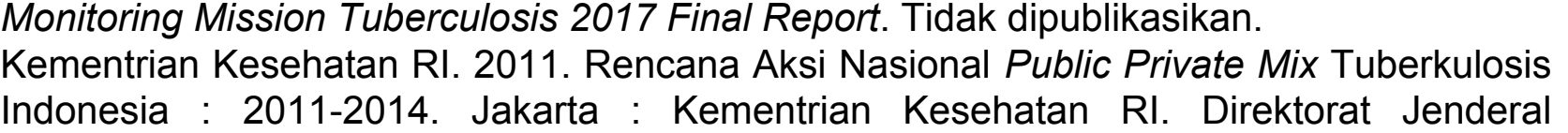
Pengendalian Penyakit dan Pennyehatan Lingkungan

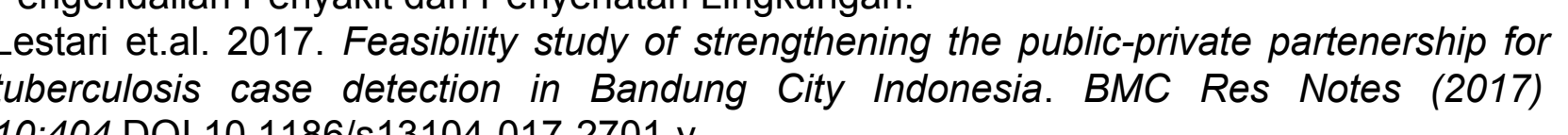

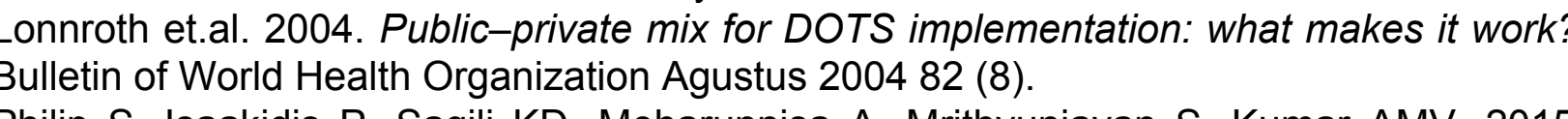

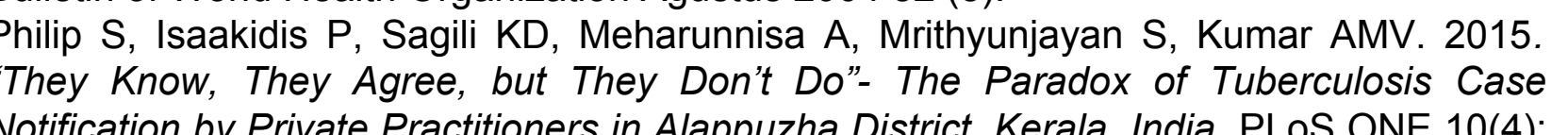

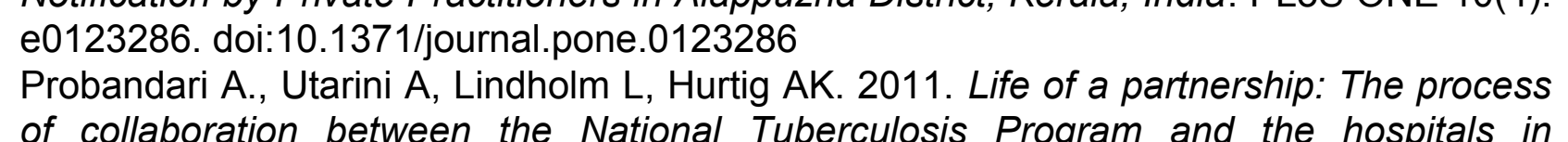

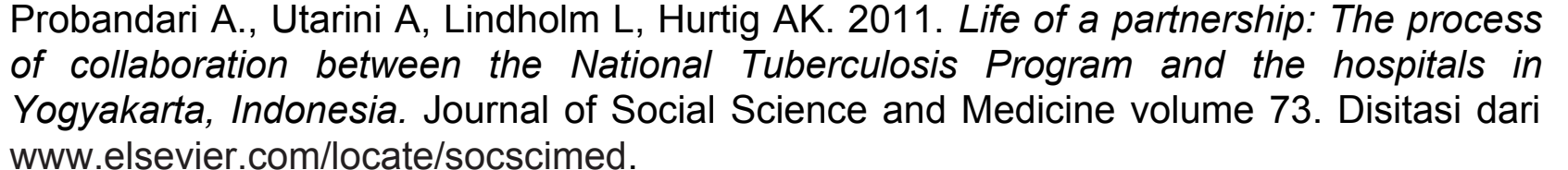

